\title{
Kidney Function in Frequent Users of Non-Steroidal Anti-Inflammatory Drugs (NSAIDs)
}

\author{
Uduagbamen PK ${ }^{1,2}$, Salako BL ${ }^{3,4}$, Hamzat MA², Kadiri S3, Arogundade FA 5 \\ ${ }^{1}$ Division of Nephrology and Hypertension, Department of Internal Medicine, Babcock University/Babcock University Teaching \\ Hospital, Ilishan-Remo, Nigeria \\ ${ }^{2}$ Nephrology Unit, Department of Internal Medicine, Federal Medical Centre, Abeokuta, Nigeria \\ ${ }^{3}$ Nephrology Unit, Department of Internal Medicine, University College Hospital, Ibadan, Nigeria \\ ${ }^{4}$ Nigerian Institute of Advanced Medical Research, Yaba, Lagos, Nigeria \\ ${ }^{5}$ Nephrology Unit, Department of Internal Medicine, Obafemi Awolowo University Teaching Hospital, Ile-Ife, Nigeria \\ Email: petr.uduagbamen@gmail.com
}

How to cite this paper: Uduagbamen PK, Salako BL, Hamzat MA, Kadiri S and Arogundade FA (2020) Kidney Function in Frequent Users of Non-Steroidal Anti-Inflammatory Drugs (NSAIDs). Open Journal of Internal Medicine, 10, 69-82.

https://doi.org/10.4236/ojim.2020.101007

Received: December 28, 2019

Accepted: March 13, 2020

Published: March 16, 2020

Copyright (C) 2020 by author(s) and Scientific Research Publishing Inc. This work is licensed under the Creative Commons Attribution International License (CC BY 4.0).

http://creativecommons.org/licenses/by/4.0/ Open Access

\begin{abstract}
Background: Non-steroidal anti-inflammatory drugs (NSAIDs) are used for managing painful conditions. They are available as cheap, over-the-counter drugs, and commonly abused. NSAIDs inhibit prostaglandins (PGs) actions on the kidneys and can cause kidney disease and hypertension, especially when used in excess doses, for prolonged period or in stressed states. Methods: The descriptive study was carried at the Orthopaedic and Family Medicine units of the Federal Medical Centre, Abeokuta. Two hundred respondents participated in the study. One hundred frequent users of NSAIDs (with daily use for $\geq 4$ weeks) and age and sex-matched controls with no known risk for kidney disease and had consented were consecutively recruited. Data were entered from history, examination and investigations (urinalysis, serum electrolyte, kidney scan and biopsy). Cases with estimated glomerular filtration rate $(\mathrm{eGFR})<60 \mathrm{mls} / \mathrm{min} / 1.73 \mathrm{~m}^{2}$ ) and dip strip proteinuria $\geq 1+$ had kidney biopsy. Statistical analysis was with SPSS 21 software. Student t-test and Chi-square tests were used to compare means and proportions respectively. Pearson's correlation test was used to determine the strength of association between independent risk factors and kidney dysfunction (KD). Results: Two hundred respondents participated in the study. Fifty one (51) females and Forty nine (49) males were recruited as cases and controls respectively. Thirteen (13) females had KD compared to 9 males, $(P=0.02)$. The mean age of cases with KD (63.04 yrs \pm 4.21$)$ was statistically higher than those without $\mathrm{KD}(\mathrm{P}=0.01)$. Majority of the cases were in the working population (30 - 59 yrs). Twenty two (22) frequent NSAIDs users had kidney dys-
\end{abstract}


function (KD) while six (6\%) controls had KD. The proportion of subjects that used herbal medicines was higher in cases with KD than in cases without $\mathrm{KD}$ as well as in the controls respectively $(\mathrm{P}=0.01)$. The mean kidney length and cortical thickness were significantly lower in cases with $\mathrm{KD}$ than in cases without $\mathrm{KD},(\mathrm{P}=0.03)$ and $(\mathrm{P}=0.017)$ respectively. The independent predictors of $\mathrm{KD}$ were increasing age, use of herbal remedies and duration of drug use. Conclusion: The prevalence of KD among frequent NSAIDs users was $22 \%$, higher than controls. Risk factors identified include increasing age, use of herbal medicines, increasing body mass index (BMI), systolic blood pressure (SBP), anaemia, reduced cortical thickness and kidney volume. NSAIDs use in excess doses, prolonged period or in stressed state increases the risk for kidney dysfunction, caution is therefore needed to avoid taking these drugs in these conditions.

\section{Keywords}

Non-Steroidal Anti-Inflammatory Drugs, Glomerular Filtration Rate, Kidney Dysfunction, Body Mass Index, Blood Pressure

\section{Introduction}

Non-steroidal anti-inflammatory drugs are used in treating painful conditions. They are among the most commonly used over-the-counter (OTC) drugs worldwide, particularly by manual labourers and the elderly. They inhibit prostaglandins (PGs) actions in the kidneys. In the kidneys, PGs cause vascular dilatation and redistribute renal blood flow from the cortex to the juxtamedullary region during periods of renal hypoperfusion. $\mathrm{PGF}_{2}$ causes diuresis and natriuresis by inhibiting sodium chloride transport at the thick ascending limb and collecting duct. $\mathrm{PGI}_{2}$ and $\mathrm{PGE}_{2}$ maintain glomerular filtration rate (GFR), $\mathrm{PGE}_{2}$ also antagonises angiotensin II actions on afferent arterioles [1].

PGs' role in the kidneys is mostly exhibited as compensatory responses in the stressed states. NSAIDs use in stressed states therefore antagonises effective renal responses by permitting unopposed release of mediators of vasoconstriction and it also causes hyporeninemic hypoaldosteronism leading to a reduction of distal tubular flow and delivery of sodium resulting in hyperkalaemia [2].

Patino et al. [3] reported that about $2 \%$ of the US population on NSAIDs stopped treatment due to renal complications of these drugs. Twelve million Americans are said to be chronic users of NSAIDs and $18 \%$ of these are taking Ibuprofen [4]. Agaba et al. [5] in a community survey in Nigeria reported the following prevalence: NSAIDs use $13 \%$, paracetamol $58.1 \%$, analgesic mixtures $28.9 \%$, analgesic abuse $22.6 \%$ and a cumulative life-long dose of $\geq 5000$ pills. Another study reported as analgesic abuse, a daily intake of any kind of analgesic during a minimum of one year and with an overall intake of at least 1000 units ( 1 unit taken as a tablet, suppository, patch or dose of powder). They found analgesic use among individuals from age 10 to 72 years and that abusers were 
mostly from the low social, economic and educational background [6]. The HANS Study in Hungary reported a high incidence of analgesic nephropathy from chronic use of NSAIDs [7].

NSAIDs metabolism results in the modification of sulphydryl (SH) group, glutathione reductase and calcium transporting ATPases (Calmodulin) leading to elevated calcium which activates cellular degrading enzymes resulting in mitochondrial damage and cytoskeletal alterations [8]. Caffeine worsens the renal outcome in people who use NSAIDs [9]. Scotney et al. [10] reported exerciseassociated hyponatremia (EAH) in long distance marathoners from dehydration causing vasopressin overproduction and this makes them more prone to analgesic nephropathy, thus recommended water intake during long distance racing. Raghavan et al. [11] reported histological findings between NSAIDs users and controls which had acute interstitial nephritis in which some resolved completely, some with residual injuries while some progressed to irreversible kidney damage. This study assessed the kidney function of frequent NSAIDs users in comparison with healthy controls.

\section{Materials and Methods}

This descriptive study was carried out at the Orthopaedic and Family Medicine units of the Federal Medical Centre, Abeokuta, Nigeria and two hundred respondents participated in the study. One hundred (51 females, 49 males) each of frequent NSAIDs users and the same number of age and sex-matched healthy controls who had no known risk factor for kidney disease, who consented, were consecutively recruited, with cases from the Orthopaedic clinic and controls from Family Medicine clinics, healthy hospital staffs and manual labourers/artisans who worked at the construction sites in the hospital.

The sample size formula for a comparative study was used viz,

$$
\begin{gathered}
\left.N=\left(2 Z^{2}\right) p q / d^{2}\right)[12] \\
N=2(1.96)^{2}(0.13)(0.87) / 0.10^{2}=87, \\
\text { calculating for attrition, }=10 / 87(100)=99 .
\end{gathered}
$$

Therefore 100 participants each were recruited as cases and as controls.

The socio-demographic parameters, history and examination findings were entered into a case record form. Data was also obtained from hospital case notes of participants. The height and weight of subjects were measured and the body mass index (BMI) was calculated. The hip and the waist circumferences $(\mathrm{cm})$ were measured according to the WHO protocol and the waist/hip ratio (WHR) was calculated. The temperature was taken using the hand-held thermometer and recorded. The systolic and diastolic blood pressure (SBP) and (DBP) in (mmHg) was taken in both sitting and standing positions using a mercury sphygmomanometer (ACCOSON, England) with an appropriate standard cuff after patients were rested for 5 minutes.

Blood was collected from an appropriate peripheral vein into an (EDTA) containing bottle for analysis of the white cell counts (WBC), and into a Lithium 
heparin bottle for serum biochemical parameters like creatinine, urea, sodium, potassium, bicarbonate and chloride. Just after needle insertion, tourniquet was released to minimize the effect of haemoconcentration.

The estimated glomerular filtration rate (eGFR) was derived from the serum creatinine using the Chronic Kidney Disease Epidemiology Collaboration (CKDEPI) formula.

Participants who had kidney dysfunction as evidenced by at least $1+$ proteinuria on dip stick and eGFR of $<60 \mathrm{mls} / \mathrm{min} / 1.73 \mathrm{~m}^{2}$ were taken for kidney biopsy after a kidney ultrasound scan

Kidneys were scanned using an ultrasound scanner (HITACHI Loci M3, Japan) with a $2.5-5.0 \mathrm{MHz}$ curvilinear transducer. Scanning was from both the front and back to determine their locations, sizes, echogenicity, corticomedullary differentiation, cortical thickness, volumes (machine-derived) and the presence or not of cysts, masses or hydronephrosis. Two consenting cases that met study criteria and had no contraindication had kidney biopsy using local anaesthesia and aseptic technique. Histological assessment was with the Heamatoxylin/Eosin (H/E) stain.

Data are expressed as mean with standard deviation using student's t-test and as proportions with chi-square. Pearson correlation test was performed to determine the significance of association between kidney dysfunction and some independent variables. Multivariate regression analysis was used to determine predictive factors of kidney dysfunction using age, duration of NSAIDs use, herbal remedies, kidney length, cortical thickness and kidney volume as independent variables. A P-value of $<0.05$ was considered statistically significant.

The study was approved by the Human Ethics Committee of the Federal Medical Centre, Abeokuta.

\section{Results}

Patient demo-graphic characteristics:

A total of two hundred participants (100 each with 51 females and 49 males) were recruited as cases and age and sex-matched controls. The mean age of the cases was $46.54 \pm 14.52$ years compared to $46.04 \pm 14.21$ years for the controls. The difference was not statistically significant $P=0.38$. The socio-demographic characteristics of the study population are shown in Table 1 . Majority of the participants had tertiary education. Seventy eight (78) cases presented on account of bone and soft tissue pain. Of this, thirty eight (38\%) had arthritis, eighteen $(18 \%)$ had low back pain, twelve (12\%) had post-fracture pain, ten $(10 \%)$ had spondylosis, and eight (8\%) had recurrent headache. Eleven $(11 \%)$ of the cases were taking herbal medicines at least thrice weekly while none of the controls used herbal remedies.

The mean clinical features of the study groups with standard deviation are shown in Table 2. There is no significant statistical difference between the mean height $(\mathrm{P}=0.56)$, WC $(\mathrm{P}=0.82)$, HC $(\mathrm{P}=0.70)$, WHR $(\mathrm{P}=0.80)$, DBP $(\mathrm{P}=0.6)$ 
Table 1. Socio-demographic characteristics of the study population.

\begin{tabular}{ccccc}
\hline Variables & Frequent NSAIDs users & Controls & $\mathrm{X}^{2}$ & P-value \\
\hline Age in years & Frequency (\%) & Frequency (\%) & & \\
\hline $20-29$ & $9(9)$ & $14(14)$ & 0.05 & 0.55 \\
$30-39$ & $23(23)$ & $20(20)$ & & \\
$40-49$ & $29(29)$ & $24(24)$ & & \\
$50-59$ & $24(24)$ & $26(26)$ & & \\
$60-69$ & $5(5)$ & $9(9)$ & & \\
$>70$ & $10(10)$ & $8(8)$ & & \\
Sex & & & & \\
Males & 49 & 49 & 0.05 & \\
Females & 51 & 51 & & \\
\hline
\end{tabular}

NSAIDs-non-steroidal anti-inflammatory drugs.

Table 2. Clinical and laboratory characteristics of the study participants.

\begin{tabular}{ccccc}
\hline Variables & NSAIDs user & Controls & t-test & P-value \\
\hline Mean $\pm(\mathrm{SD})$ & Mean $\pm(\mathrm{SD})$ & & & \\
\hline Height $(\mathrm{m})$ & $1.6 \pm 0.09$ & $1.6 \pm 0.08$ & 0.02 & 0.56 \\
Weight $(\mathrm{kg})$ & $71.74 \pm 14.92$ & $67.72 \pm 12.54$ & 3.10 & 0.03 \\
BMI & $28.12 \pm 13.11$ & $26.47 \pm 13.21$ & 3.04 & 0.03 \\
Waist $(\mathrm{cm})$ & $93.90 \pm 14.64$ & $94.13+13.72$ & 0.02 & 0.82 \\
Hip $(\mathrm{cm})$ & $92.81 \pm 12.36$ & $93.42 \pm 10.05$ & 0.02 & 0.70 \\
WHR & $1.00 \pm 0.10$ & $1.00 \pm 0.04$ & 0.01 & 0.80 \\
SBP $(\mathrm{mmHg})$ & $123.50 \pm 10.46$ & $114.0 \pm 11.70$ & 5.92 & $<0.001$ \\
DBP $(\mathrm{mmHg})$ & $75.73+8.26$ & $74.53+7.20$ & 0.03 & 0.6 \\
Sodium $(\mathrm{mmol} / \mathrm{l})$ & $134.56 \pm 7.62$ & $136.87 \pm 1.43$ & 1.82 & 0.08 \\
Potassium $(\mathrm{mmol} / \mathrm{l})$ & $4.10 \pm 2.82$ & $3.82 \pm 6.04$ & 2.02 & 0.03 \\
Chloride $(\mathrm{mmol} / \mathrm{l})$ & $102.67 \pm 8.23$ & $96.15 \pm 1.88$ & 7.34 & $<0.001$ \\
Bicarbonate $(\mathrm{mmol} / \mathrm{l})$ & $22.56 \pm 10.47$ & $23.94+9.0$ & 2.32 & 0.04 \\
Urea $(\mathrm{mg} / \mathrm{dl})$ & $37.91 \pm 3.22$ & $32.08 \pm 4.47$ & 2.86 & 0.04 \\
Creatinine $(\mathrm{mg} / \mathrm{dl})$ & $1.11 \pm 0.33$ & $0.88 \pm 0.18$ & 5.72 & $<0.001$ \\
eGFR CKD-EPI (ml/min) & $87.83 \pm 30.72$ & $115.01 \pm 26.92$ & 14.42 & $<0.001$ \\
Haemoglobin $(\mathrm{g} / \mathrm{dl})$ & $12.78 \pm 1.26$ & $13.83 \pm 1.42$ & 2.48 & 0.02 \\
\hline
\end{tabular}

$\mathrm{BMI}=$ body mass index, $\mathrm{WHR}=$ waist hip ratio, $\mathrm{SBP}=$ systolic blood pressure, $\mathrm{DBP}=$ diastolic blood pressure, $\mathrm{S}=$ serum, eGFR = estimated glomerular filtration rate, CKD-EPI = chronic kidney disease epidemiology initiative, $\mathrm{p}<0.05$ is significant.

of the frequent NSAIDs users and controls. There was a significant statistical difference between the mean weight, BMI and SBP of the NSAIDs users and the controls, $\mathrm{P}=0.03, \mathrm{P}=0.03$ and $\mathrm{P} \leq 0.001$ respectively. There was no significant statistical difference between mean serum sodium of the frequent NSAIDs users and the controls, $\mathrm{P}=0.8$. However, there was a significant statistical difference between the mean serum potassium, chloride, bicarbonate, urea, creatinine, eGFR and $\mathrm{Hb}$ concentration of the NSAID users and the controls, $\mathrm{P}=0.03, \mathrm{P} \leq$ $0.001, \mathrm{P}=0.04), \mathrm{P}=0.04, \mathrm{P} \leq 0.001, \mathrm{P} \leq 0.001)$ and $\mathrm{P}=0.02$ respectively.

A greater proportion of NSAIDs users had shrunken kidneys $(<9 \mathrm{~cm})$ compared with the controls though the difference was not statistically significant, $\mathrm{P}=$ 0.3 . There was a statistically significant difference between the mean cortical 
thickness of the frequent NSAIDs users and controls $P=0.01$. A significantly greater proportion of NSAIDs users had kidneys with increased echogenicity grades than the controls, $\mathrm{P}<0.001$. There was a statistically significant difference between the kidney volumes of NSAIDs users and controls, $\mathrm{P}<0.001$. The renal ultrasound findings of the NSAIDs users are compared with controls in Table 3.

The eGFR distribution of the NSAIDs users is compared with controls in Table 4. Twenty two of the NSAIDs users compared to 6 in the controls had kidney dysfunction (eGFR. $<60 \mathrm{ml} / \mathrm{min}$ ), none of the participants had end stage kidney disease but more NSAIDs users were in the higher levels of the GFR staging of kidney disease. As the duration of NSAIDs use increased, the eGFR reduces. The relationship between the duration of NSAIDs use and the eGFR is shown in Table 5. Participants that took NSAIDs for less than 6 months had a mean eGFR of $96.26 \pm 16.30$ while those that took NSAIDs for up to 5 years had a mean eGFR of $67.55 \pm 12.28$.

Table 6 shows Pearson correlation used to determine the strength of association between kidney dysfunction (KD) and age, duration of drug use, BMI, haemoglobin concentration, kidney length, cortical thickness, and volume. KD was not strongly associated with kidney length and volume but was strongly associated with age, duration of NSAIDs use, Hb conc, BMI and cortical thickness.

Table 7 shows multiple regression analysis from which, age of NSAIDs users $(\mathrm{OR}=1.72, \mathrm{CI}=1.06-2.78)$, duration of use $(\mathrm{OR}=1.68, \mathrm{CI}=1.02-264)$, use of herbal remedies $(62.77, \mathrm{CI}=3.45-1142)$, mean cortical thickness $(\mathrm{OR}=0.032$, CI-0.003 - 0.036) and kidney length $(\mathrm{OR}=9.46, \mathrm{CI}=1.14-78.28)$ predicted kidney dysfunction. The cumulative lifetime dose of NSAIDs was calculated as

Table 3. Comparing the kidney ultrasound findings of the NSAIDs users with controls.

\begin{tabular}{|c|c|c|c|c|}
\hline Variables & NSAIDs users & Controls & $\mathrm{X}^{2}$ & P-value \\
\hline \multirow[t]{2}{*}{ Kidney sizes } & Frequency (\%) & Frequency (\%) & & \\
\hline & $\mathrm{n}=100$ & $\mathrm{n}=100$ & & \\
\hline \multicolumn{5}{|l|}{ Length } \\
\hline$(\geq 9 \mathrm{~cm})$ & 75 & 79 & 0.45 & 0.3 \\
\hline$(<9 \mathrm{~cm})$ & 25 & 21 & & \\
\hline \multicolumn{5}{|c|}{ Cortical thickness } \\
\hline$(\geq 7 \mathrm{~mm})$ & $78(78)$ & $93(93)$ & 9.07 & 0.01 \\
\hline$(<7 \mathrm{~mm})$ & $22(22)$ & $7(7)$ & & \\
\hline \multicolumn{5}{|l|}{ Echo grade } \\
\hline (0) & $71(71)$ & $91(91)$ & 12.99 & $<0.001$ \\
\hline$(\geq 1)$ & $29(29)$ & $9(9)$ & & \\
\hline \multicolumn{5}{|l|}{ Volume } \\
\hline$\left(\geq 50 \mathrm{~cm}^{3}\right)$ & $75(75)$ & $92(92)$ & 12.48 & $<0.001$ \\
\hline$\left(<50 \mathrm{~cm}^{3}\right)$ & $25(25)$ & $8(8)$ & & \\
\hline
\end{tabular}

LK-left kidney; RK—right kidney; Kidney echogenicity grades: 0 (<liver, good CMD); 1 (liver, good CMD); 2 (>liver, good CMD); 3 (>liver, partial loss of CMD); 4 (>liver, total loss of CMD). 
Table 4. Distribution of the study population based on eGFR.

\begin{tabular}{|c|c|c|c|c|c|}
\hline Variables & Stage & $\begin{array}{l}\text { NSAIDs users } \\
\text { Frequency (\%) }\end{array}$ & $\begin{array}{c}\text { Controls } \\
\text { Frequency (\%) }\end{array}$ & $\mathrm{X}^{2}$ & $\mathrm{P}$-value \\
\hline & & $\mathrm{n}=100$ & $\mathrm{n}=100$ & & \\
\hline \multicolumn{6}{|l|}{$\begin{array}{c}\text { eGFR } \\
(\mathrm{ml} / \mathrm{min})\end{array}$} \\
\hline$\geq 90$ & 1 & 47 & 81 & 13.54 & $<0.001^{*}$ \\
\hline $60-89$ & 2 & 31 & 13 & & \\
\hline $45-59$ & $3 a$ & 10 & 6 & & \\
\hline $30-44$ & $3 b$ & 11 & 0 & & \\
\hline $15-29$ & 4 & 1 & 0 & & \\
\hline$<15$ & 5 & 0 & 0 & & \\
\hline
\end{tabular}

${ }^{\star}$ fisher's exact test, eGFR-estimated glomerular filtration rate.

Table 5. Relationship between duration of NSAIDs use and glomerular filtration rate.

\begin{tabular}{cccc}
\hline Variables & Mean GFR & $\mathrm{X}^{2}$ & P-value \\
\hline Duration & & & \\
$1-5.99$ mths & $96.26 \pm 16.30$. & 11.82 & \\
$6-11.99$ mths & $92.44 \pm 14.52$ & \\
$1-4.99$ yrs & $80.90 \pm 18.72$ & \\
$>5$ yrs & $67.55 \pm 12.28$ & \\
\hline
\end{tabular}

NSAIDs—-non steroidal anti-inflammatory drugs; GFR—glomerular filtration rate; KD—kidney dysfunction.

Table 6. The strength of association between kidney dysfunction and some variables.

\begin{tabular}{ccc}
\hline Variables & $\begin{array}{c}\text { Pearson's correlation } \\
\text { Coefficient }\end{array}$ & P-value \\
\hline Age & 0.92 & 0.001 \\
Duration of NSAIDs use & 0.35 & 0.01 \\
BMI & 0.21 & 0.04 \\
Hb & 0.32 & 0.001 \\
Kidney length & 0.28 & 0.05 \\
Cortical thickness & 0.31 & $<0.001$ \\
Kidney volume & 0.18 & 0.5 \\
\hline
\end{tabular}

NSAIDs = non-steroidal anti-inflammatory drugs, $\mathrm{BMI}=$ body mass index, $\mathrm{Hb}=$ haemoglobin concentration .

Table 7. Multivariate logistic regression analysis.

\begin{tabular}{cccc}
\hline Variables & OR & $95 \%$ CI & P-value \\
Age in years & 1.72 & $1.06-2.78$ & 0.02 \\
Herbal remedies & 62.77 & $3.45-1142.07$ & 0.01 \\
Duration of NSAIDs use (years) & 1.68 & $1.02-264$ & 0.02 \\
Mean kidney length & 9.46 & $1.14-78.28$ & 0.03 \\
Mean cortical thickness & 0.032 & $0.003-0.036$ & 0.01 \\
Mean kidney volume & 1.00 & $0.99-1.23$ & 0.05 \\
\hline
\end{tabular}

OR-odd ratio, CI-confidence interval, NSAIDs-non steroidal anti-inflammatory drugs. 
the average weekly dose (number of tablets, capsule or patch or any other) multiplied by fifty two (52) multiplied by number of years of drug(s) use. The cumulative life time dose of NSAIDs was determined by statistical method using the Mann-Whitney Test as shown in Table 8. The mean rank of cases with KD was higher than for cases without KD (62.39 vs 47.15), likewise, the cumulative lifetime dose of NSAIDs of cases with KD was higher than for cases without KD (2306.4 vs 1292.9). The difference was statistically significant $P=0.02$.

Two consenting cases which met the study's criteria and had no contraindication to, underwent kidney biopsy. The first was a 62-year-old with daily use of Diclofenac for 6 weeks, whose histological result is shown in Figure 1. The second was a 54-year-old man that used Miloxicam daily for 14 months, his histological finding is shown in Figure 2.

Histology report 1:

There is widespread mononuclear cellular infiltrate into the interstitium. There is tubular basement membrane disruption, some with wall dilatation. Some tubules are scarcely visible due to the inflammatory changes and damages. Also seen is glomerular sclerosis with glomerular basement membrane detachment showing chronic glomerular injury.

Assessment: Acute interstitial nephritis with tubular necrosis and background chronic glomerular injury.

Table 8. Cumulative life time dose of frequent NSAIDs users.

\begin{tabular}{cccccc}
\hline & $\begin{array}{c}\text { Frequency } \\
(\%)\end{array}$ & Mean rank & $\begin{array}{c}\text { Cumulative } \\
\text { lifetime dose }\end{array}$ & U & P-value \\
\hline Cases without KD & $78(78)$ & 47.15 & 1292 & 596.50 & 0.02 \\
Cases with KD & $22(22)$ & 62.39 & 2306 & & \\
\hline
\end{tabular}

NSAIDs $=$ non-steroidal anti-inflammatory drugs, $\mathrm{KD}=$ kidney dysfunction.

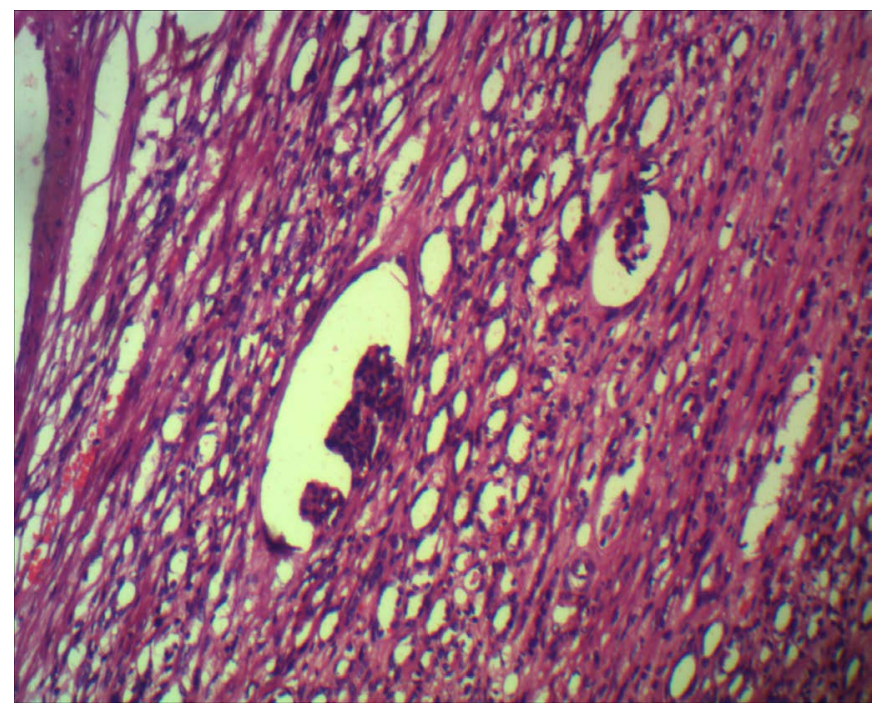

Figure 1. Photomicrograph showing histological findings in a 62-year-old man with a 6-week history of daily use of Diclofenac sodium $100 \mathrm{mg}$ and occasionally, meloxicam $(\times 800)$. 


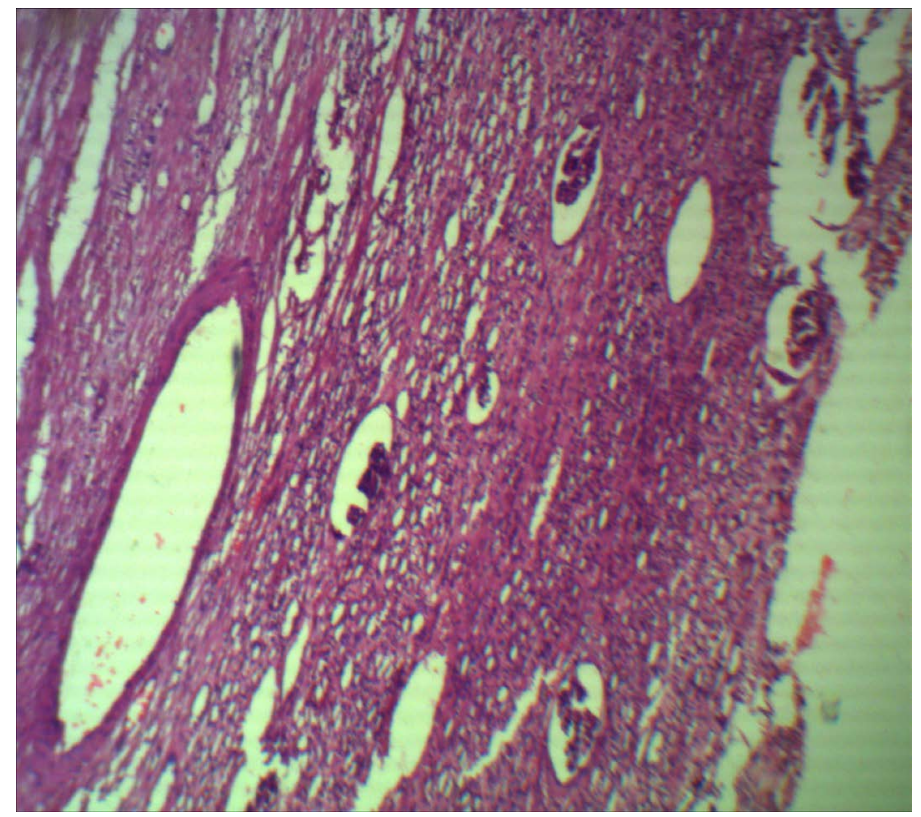

Figure 2. Histological findings in a 54-year-old man with a 14-month history of daily Miloxicam 15 mg use $(\times 400)$.

\section{Histology Report 2:}

There is widespread infiltration of the interstitium by mononuclear inflammatory cells and some polymorphonuclear cellular infiltrates are also seen. Tubular atrophy and tubular basement membrane with wider spacing of tubules due to chronic injury as well as some eosinophilic microabscesses are seen. Furthermore, although glomeruli are seen, most are with sclerosis and detachment of the glomerular basement membrane.

Assessment: Chronic tubulointerstitial nephritis with tubular dilatation.

\section{Discussion}

The kidney functions of frequent NSAIDs users were assessed in this study. The study found a prevalence rate of KD (based on eGFR $<60 \mathrm{ml} / \mathrm{min}$ and dip stick proteinuria of $\geq 1+$ ) amongst frequent NSAIDs users of $22 \%$ as against $6 \%$ in the control population. This is similar to findings by Schwarz et al. [13] and De Broe et al. [14] who found $19 \%$ and $17 \%$ prevalence respectively among the NSAIDs users. Freedman et al. [15] reported an increased risk of nephropathy among people of African ancestry in genetic studies that implicated APO1. The prevalence of KD was high in this study as it was carried out entirely on black Africans amongst whom herbal remedies are commonly used. Kadiri et al. [16] also reported a high prevalence of use of herbal remedies with attendant nephrotoxicities. Herbal medicines can induce a non-inflammatory glomerulopathy that could be fatal due to concurrent reduction in glomerular filtration as well as non-clearance of cytokines, sloughed epithelial cells and lysosomal aggregates from the tubular lumen and wall. Again, the earlier studies used the older formulae for determining the eGFR (MDRD and/or Cockkcroft gault) which are 
known to overestimate the eGFR when it is less than $60 \mathrm{ml} / \mathrm{min}$, unlike the CKD-EPI formula used in the index study, therefore some of the cases would have been classified as not having KD if these earlier equations were used [17].

A greater proportion of women were found to have kidney dysfunction than men in this study. Sean et al. [18] and Chang et al. [19] reported separately that NSAIDs induced nephropathy was more likely to develop in women than in men. This could be attributed to various factors viz; Females have lesser weight and since most drugs for adults are not prescribed per body weight, females tend to use more quantity compared with their body weight. Females, also, have more body fats and by extension higher volume of distribution of drugs, therefore, greater risk of toxicities especially in excessive doses [8]. Females have lesser activity of most of the cytochrome P450 inducer enzymes systems (with lesser clearance) thus leading to higher blood concentrations of drugs with attendant toxicities. There is reduced renal clearance of unchanged (less polar) drugs and this is further worsened by the comparatively lower glomerular filtration rate in females. The weight of these factors is enormous, probably overriding the known fact that kidney diseases are commoner in males due to their higher sensitivity to renin angiotensin aldosterone (RAAS) stimulation and lesser responsiveness to RAAS blockage after 8 weeks of therapy as reported by Miller et al. [20].

Increasing age was found as a risk factor for the development of NSAIDs induced kidney dysfunction. Sean et al. [18] and Okoye et al. [21] both documented that increasing age was a risk factor for developing kidney dysfunction. Longer duration of use of NSAIDs was associated with more derangement in kidney function in this study. Schwartz et al. [13] reported that subjects that used NSAIDs for more than 4 weeks were more likely to suffer substantial injury and progress to chronic kidney disease. This could be due to the recurrent circles of injury followed by repair/healing associated with reperfusion injury eventually leading to healing by fibrosis, calcification and kidney scaring.

This study found an increasing BMI and abnormal WHR as risk factors for developing KD amongst NSAIDs users. Kovesty et al. [22] found that obesity associated hyperfiltration leads to increased intraglomerular pressure and kidney damage. Increasing mean SBP and DBP were found to be risk for developing KD in this study. Similar findings were reported by Barri et al. [23] and other studies linking elevated SBP and DBP to KD in NSAIDs users. The relationship between microalbuminuria in hypertensives and progression to CKD has long been reported in various studies.

Anaemia $(\mathrm{Hb}<13 \mathrm{mg} / \mathrm{dl})$ was 2.5 times more common among the NSAIDs users compared to controls. Goldstein et al. [24] found up to $2 \mathrm{~g} / \mathrm{dl}$ reduction in haemoglobin concentration over time in NSAIDs users in two large independent trials. This relatively high prevalence of anaemia among these patients with KD could be attributed to the fact that the interstitium which is mostly affected by NSAIDs, is the site of erythropoietin production in the kidneys.

The overall derangement in kidney function (serum parameters) found in this 
study is also reported by various authors. This is mostly from NSAIDs-induced inhibition of PGs mediated renal vasodilatation leading to reduced GFR as against an increase needed in stressed states. This renal hypoperfusion leads to its reduced excretory functions and blood accumulation of nitrogenous waste [25] [26].

In this study, all kidney radiological indices were abnormal in NSAIDs users, more so in NSAIDs users with kidney dysfunction. Beland et al. [27] found that reduced kidney sizes with increased echogenicity were found more in people with kidney dysfunction than in healthy controls. Although kidney sizes may be normal or increased in the initial phase of NSAIDs induced injury (from compensatory renal hypertrophy and hyperfiltration), prolonged NSAIDs use induces a chronic injurious state mediated by an upregulation of the RAAS resulting in renal fibrosis and shrinkage [28]. This can progress to small indented, calcified kidneys (SICK syndrome) seen in analgesic nephropathy [13] [29] [30]. Disease progression involves progressive reduction in sizes, cortical thickness and blunting of the corticomedullary differentiation [31].

Histologic findings in this study revealed predominant interstitial and tubular cells affectation as also reported by Postishil Iua et al. [32]. In acute injury, there is proliferation of acute inflammatory cells into the interstitium and adjoining tubules whereas in prolonged use, there is mononuclear cellular infiltration (with paucity of polymorphs), mesenchymal cells and laying down of collagen, leading to tubular atrophy, tubular basement membrane thickening, wall dilatation and interstitial fibrosis [33].

\section{Conclusion}

The prevalence of KD in frequent NSAIDs users in this study was $22 \%$. This is quite high considering the fact that respondents with hypertension and diabetes were excluded. Females, advancing age, longer duration of NSAIDs use and herbal remedies are factors that appear to confer a higher risk of developing KD in frequent NSAIDs users. It is therefore imperative that all measures needed are taken to reduce NSAIDs use particularly in stressed states.

\section{Limitations}

1) The study did not include radiological investigations like computed tomography (CT) and magnetic resonance imaging which are needed for validation of analgesic nephropathy (when present).

2) All investigations were done by one point test. Therefore chronicity of dysfunction could not be confirmed.

3) Genetic studies for ApoL-1 could not be done due to lack of facilities and prohibitive price.

4) The main definition of the study did not include the most commonly used OTC analgesic, paracetamol because of its relatively low nephrotoxicity even though prolonged high doses may be nephrotoxic. 
5) Subjects with chronic pain may under or over-estimate the duration and frequency of NSAIDs use especially those not prescribed.

6) Information on comorbid conditions was self-reported and also gotten from subjects' case notes, disease conditions that could affect results could be present without been discovered.

\section{Conflicts of Interest}

The authors declare no conflicts of interest regarding the publication of this paper.

\section{References}

[1] Kim, G.-H. (2008) Renal Effects of Prostaglandins and Cyclooxygenase-2 Inhibitors. Electrolyte Blood Press, 6, 35-41. https://doi.org/10.5049/EBP.2008.6.1.35

[2] Whelton, A. (2002) COX-2-Specific Inhibitors and the Kidneys: Effect on Hypertension and Oedema. Journal of Hypertension. Supplement, 20, S31-S35.

[3] Patino, F.G., Olivieri, J. and Allison, J.J. (2003) Non-Steroidal Anti-Inflammatory Drug Toxicity Monitoring and Safety Practices. The Journal of Rheumatology, 30, 2680-2688.

[4] Paulose-Ram, R., Hirsch, R., Dillon, C., Losonczy, K., Cooper, M. and Ostchega, Y. (2003) Prescription and Non-Prescription Analgesic Use among the US Adult Population: Results from the Third National Health and Nutrition Examination Survey (NHANES III). Pharmacoepidemiology and Drug Safety, 12, 315-326. https://doi.org/10.1002/pds.755

[5] Agaba, E.L., Agaba, P.A. and Wigwe, C.M. (2004) Use and Abuse of Analgesic in Nigeria. Nigerian Journal of Medicine, 13, 379-382.

[6] Elseviers, M.M. and De Broe, M.E. (1995) A Long-Term Prospective Controlled Study of Analgesic Abuse in Belgium. Kidney International, 48, 1912-1919. https://doi.org/10.1038/ki.1995.491

[7] Pintér, I., Mátyus, J. and Czégány, Z. (2004) Analgesic Nephropathy in Hungary: The HANS Study. Nephrology Dialysis Transplantation, 19, 840-843. https://doi.org/10.1093/ndt/gfh040

[8] Gonzalez, F.J. and Tukey, R.H. (2006) Drug Metabolism. In: Goodman \& Gilman's Pharmacological Basis of Therapeutics, 11th Edition, Chapter 3, McGraw-Hill, Brunton, LL, 23-31.

[9] Horl, W.H. (2010) Nonsteroidal Anti-Inflammatory Drugs and the Kidney. Pharmaceutical, 3, 2291-2321. https://doi.org/10.3390/ph3072291

[10] Scotney, B. and Reid, S. (2015) Body Weight, Serum Sodium Levels and Renal Function in an Ultra-Distance Mountain Run. Clinical Journal of Sport Medicine, 25, 341-346. https://doi.org/10.1097/JSM.0000000000000131

[11] Raghavan, R. and Eknoyan, G. (2014) Acute Interstitial Nephritis: A Reappraisal and Update. Clinical Nephrology, 82, 149-162. https://doi.org/10.5414/CN10838

[12] Araoye, M.O. (2003) Sample Size Determination. In: Margaret, O.A., Ed., Research Methodology with Statistics for Health and Social Sciences, Nathadex Publishers, Ilorin, Nigeria, 115-119.

[13] Schwarz, A., Krause, P.H., Kunzendrof, V., Keller, F. and Distler, A. (2000) The Outcome of Acute Interestial Nephritis: Risk Factors for the Transition from Acute to Chronic Interstistial Nephritis. Clinical Nephrology, 54, 179-190. 
[14] De Broe, M.E. and Elseviers, M.M. (2009) Over-the-Counter Analgesic Use. Journal of the American Society of Nephrology, 20, 2098-2103. https://doi.org/10.1681/ASN.2008101097

[15] Freedman, B.L. (2003) APOL 1 and Nephropathy Progression in African Ancestry. Seminars in Nephrology, 33, 425-432. https://doi.org/10.1016/j.semnephrol.2013.07.004

[16] Kadiri, S., Arije, A. and Salako, B.L. (1999) Traditional Herbal Preparations and Acute Renal Failure in South West Nigeria. Tropical Doctor, 29, 244-246. https://doi.org/10.1177/004947559902900419

[17] Levey, A.S., Stevens, L.A., Schmid, C.H., Zhang, Y.L., Castro, A.F., Feldman, H.I., et al. (2009) CKD-EPI (Chronic Kidney Disease Epidemiology Collaboration) A New Equation to Estimate Glomerular Filtration Rate. Annals of Internal Medicine, 150, 604-612. https://doi.org/10.7326/0003-4819-150-9-200905050-00006

[18] Sean, H.C., Timothy, H.M. and McDonald, S.P. (2008) Analgesic Nephhropathy and Renal Replacement Therapy in Australia: Trend, Comobidities and Outcomes. Clinical Journal of the American Society of Nephrology, 3, 768-777. https://doi.org/10.2215/CJN.04901107

[19] Chang, S.H., Mathew, T.H. and McDonald, S.P. (2008) Analgesic Nephropathy and Renal Replacement Therapy in Australia: Trends, Comorbidities and Outcomes. Clinical Journal of the American Society of Nephrology, 3, 768-776. https://doi.org/10.2215/CJN.04901107

[20] Miller, J.A., Cherney, D.Z., Duncan, J.A., Lai, V., Burns, K.D., Kennedy, C.R.J., et al. (2006) Gender Difference in the Renal Response to Renin Angiotensin System Blockage. Journal of the American Society of Nephrology, 17, 2554-2560. https://doi.org/10.1681/ASN.2005101095

[21] Okoye, O.C.A., Oviasu, E. and Ojogwu, L. (2011) Prevalence of Chronic Kidney Disease and Its Risk Factors amongst Adults in a Rural Population in Edo State, Nigeria. Journal of US-China Medical Science, 8, 471-481.

[22] Kovesty, C.P., Furth, S.L. and Zoccali, C. (2017) Obesity and Kidney Disease: Hidden Consequences of the Epidemic. Journal of Nephrology, 30, 1-10. https://doi.org/10.1007/s40620-017-0377-y

[23] Barri, Y.M. (2008) Hypertension and Kidney Disease: A Deadly Connection. Current Hypertension Reports, 10, 39-45. https://doi.org/10.1007/s11906-008-0009-y

[24] Goldstein, J.L., Chan, F.K.L., Lanas, A., Wilcox, C.M., Peura, D. and Sands, G.H. (2011) Haemoglobin Reduction in NSAIDs Users over Time: An Analysis of 2 Large Outcome Trials. Alimentary Pharmacology \& Therapeutics, 34, 808-816. https://doi.org/10.1111/j.1365-2036.2011.04790.x

[25] Gooch, K., Culleton, B.F., Manns, B.J., Zhang, J., Alfonso, H., Tonelli, M., et al. (2007) NSAIDs Use and Progression of Chronic Kidney Disease. American Journal of Medicine, 120, 280.e1-280.e7. https://doi.org/10.1016/j.amjmed.2006.02.015

[26] Levey, A.S., Coresh, J., Bolton, K., Culleton, B., Harvey, K.S., Ikizler, T.A., et al. (2002) K/DOQI Clinical Practice Guidelines for Chronic Kidney Disease Evaluation, Classification and Stratification. American Journal of Kidney Diseases, 39, S1-S266.

[27] Mackinnon, B., Boulton Jone, M. and Mclaughlin, K. (2003) Analgesic-Associated Nephropathy in the West of Scotland: A 12 Year Observational Study. Nephrology Dialysis Transplantation, 18, 1800-1809. https://doi.org/10.1093/ndt/gfg230

[28] Yaxley, J. (2016) Common Analgesic Agents and Their Roles in Analgesic Nephropathy: A Commentary on the Evidence. The Korean Journal of Medicine, 37, 
310-316. https://doi.org/10.4082/kjfm.2016.37.6.310

[29] Rexrode, K.M., Buring, J.E., Glynn, R.J., Stampfer, M.J., Youngman, L.D. and Gaziano, J.M. (2001) Analgesic Use and Renal in Men. The Journal of the American Medical Association, 286, 315-321. https://doi.org/10.1001/jama.286.3.315

[30] Beland, M.D., Walle, N.L., Machan, J.T. and Cronan, J.J. (2010) Renal Cortical Thickness Measured at Ultrasound: Is It Better than Renal Length as an Indicator of Renal Function in Chronic Kidney Disease? American Journal of Roentgenology, 195, 146-149. https://doi.org/10.2214/AJR.09.4104

[31] Brown, P. (2003) Ultrasound in Diffuse Renal Disease. British Medical Ultrasound Society's Bulletin, 11, 30-34. https://doi.org/10.1177/1742271X0301100406

[32] Postshil, I.A. (1995) Pathomorphology of Kidney Lesions Induced by NSAIDs. Arkhiv Patologii, 57, 70-74.

[33] Mihovilovic, K., Ljubanovic, D. and Knotek, M. (2011) Safe Administration of Celecoxib to a Patient with Repeated Episodes of Nephrotic Syndrome Induced by NSAIDs. Clinical Drug Investigation, 31, 351-355.

https://doi.org/10.1007/BF03256934 